\title{
Expresión de marcadores en células dendríticas de pacientes chagásicos crónicos estimuladas con la proteína KMP-11 y el péptido K1 de Trypanosoma cruzi
}

\author{
Sandra Paola Santander ${ }^{1+}$, Adriana Cuéllar Ávila ${ }^{2+}$, María del Carmen Thomas ${ }^{3}$, \\ Fanny Guzmán ${ }^{4}$, Alberto Gómez Gutiérrez ${ }^{5}$, Manuel Carlos López ${ }^{3}$, \\ Concepción Puerta Bula ${ }^{1}$ \\ 1 Laboratorio de Parasitología Molecular, Departamento de Microbiología, Facultad de Ciencias, Pontificia \\ Universidad Javeriana, Bogotá, D.C., Colombia. \\ 2 Laboratorio de Inmunobiología y Biología Celular, Departamento de Microbiología, Facultad de Ciencias, \\ Pontificia Universidad Javeriana, Bogotá, D.C., Colombia. \\ 3 Departamento de Biología Molecular, Instituto de Parasitología y Biomedicina López Neyra, CSIC, Granada, \\ España. \\ 4 Facultad de Medicina, Universidad Nacional de Colombia, Bogotá, D.C., Colombia \\ 5 Instituto de Genética Humana, Facultad de Medicina, Pontificia Universidad Javeriana, Bogotá, D.C., \\ Colombia. \\ + Autores con participación equivalente en el trabajo.
}

Introducción. La proteína de membrana 11 de kinetoplástidos, KMP-11, de Trypanosoma cruzi induce inmunidad humoral y celular en ratones capaz de conferir protección frente al reto con el parásito.

Objetivo. Determinar la expresión de marcadores de maduración en las células dendríticas de pacientes chagásicos crónicos e individuos sanos, estimuladas con la proteína KMP-11 y su péptido amino terminal K1.

Materiales y métodos. Monocitos de siete pacientes chagásicos y siete individuos sanos fueron diferenciados a células dendríticas y estimulados con la proteína KMP-11 y el péptido K1, determinándose por citometría de flujo y tras 7 días de cultivo, la expresión de los marcadores de superficie CD83, CD86 y HLA-DR y la producción de citocinas.

Resultados. La proteína KMP-11 y el péptido K1 no indujeron la expresión del marcador de maduración CD83 en las células dendríticas de pacientes y controles. La exposición de células dendríticas de pacientes chagásicos de forma simultánea al péptido K1 y LPS mostró una disminución de la expresión de CD86 y CD83 con relación a la estimulación con LPS sólo, a diferencia de las células de controles sanos. También se evidenció una disminución en la producción de interleucina-12 en las células dendríticas de pacientes en relación a las de los controles.

Conclusiones. La proteína KMP-11 no tiene un efecto significativo sobre la maduración de las células dendríticas, pero su péptido K1 en presencia de LPS induce una disminución en la expresión de CD86 y CD83 y en la producción de la interleucina-12 que podría modular la respuesta inmune in vivo y en particular la estimulación de los linfocitos $\mathrm{T}$.

Palabras clave: enfermedad de Chagas, interleucina-12, Trypanosoma cruzi

Expression of markers on dendritic cells from chronic chagasic patients stimulated with the KMP-11 protein and the K1 peptide from Trypanosoma cruzi

Introduction. The kinetoplastid membrane protein 11, KMP-11, from Trypanosoma cruzi elicits humoral and cellular immunity in mice that protects them from infection against further parasite challenge.

Objective. To characterize the expression of surface markers on dendritic cells from chronic chagasic patients and healthy individuals, in response to the KMP-11 protein from Trypanosoma cruzi and its N-terminal peptide $\mathrm{K} 1$. 


\begin{abstract}
Materials and methods. Monocyte-derived dendritic cells from seven chronic chagasic patients and seven healthy individuals were stimulated with the KMP-11 protein and the K1 peptide. Seven days after culturing, the CD83, CD86, and HLA-DR membrane expression as well as the production of cytokines were evaluated by flow cytometry.

Results. Neither KMP-11 protein nor K1 peptide elicited the expression of the maturation marker CD83 on dendritic cells of patients or healthy control individuals. Dendritic cells from chronic chagasic patients exposed to K1 and LPS at the same time presented a significant reduction in CD86 and CD83 membrane expression in contrast to the cells exposed to LPS alone, whereas dendritic cells from healthy individuals did not show this behavior. The secretion of interleukin-12 was decreased in the cultures of dendritic cells from chronic chagasic patients but not from healthy controls.

Conclusions. KMP-11 protein does not affect the maturation of dendritic cells, but in the presence of LPS the K1 peptide leads to a decreased expression of CD86 and CD83 as well as interleukin12 production, This phenomenon may be associated with an impaired T cell stimulation.
\end{abstract}

Key words: Chagas disease, Interleukin-12, Trypanosoma cruzi

Las células dendríticas estimulan linfocitos $T$ maduros que no han tenido contacto con el antígeno gracias a la alta expresión de moléculas del complejo mayor de histocompatibilidad, moléculas coestimuladoras como CD80 y CD86 y moléculas de adhesión como ICAM-1 e ICAM-3 (1). En la periferia, las células dendríticas se especializan para capturar antígenos por endocitosis mediada por receptor o macropinocitosis, y una vez activadas por antígenos, migran a los órganos linfoides proximales (2). Durante esta migración pierden capacidad fagocítica y aumentan la expresión de las moléculas relacionadas con la presentación antigénica, proceso conocido como maduración. Una vez en los órganos linfoides, las células dendríticas maduras tienen un papel importante en la instrucción de las células T para definir su polarización hacia una respuesta Th1 o Th2 (3).

Trypanosoma cruzi es un parásito protozoo hemoflagelado, agente causal de la enfermedad de Chagas, entidad que afecta a 18 millones de personas en 15 países endémicos, con una incidencia anual de 200.000 nuevos casos (4). En Colombia, se estima que hay cerca de 700.000 personas infectadas, un $23 \%$ de la población en riesgo de contraer la enfermedad y entre 30 y 40 mil nuevos casos anuales (5).

\footnotetext{
Correspondencia:

Concepción Puerta

Tel.:(+571) 3208320 ext 4024, Fax (571) 3208320, ext 4021 cpuerta@javeriana.edu.co
}

Recibido: 19/08/05; aceptado: 27/12/05
La mayoría de humanos infectados por este parásito sobreviven a la fase aguda inicial, pero algunos desarrollan enfermedad crónica, lo cual indica que la respuesta generada en estos individuos no es capaz de controlar la infección, permitiendo la supervivencia del parásito en los tejidos y dando lugar al desarrollo de lesiones focales inflamatorias, características de la fase crónica de la enfermedad (6).

Varias líneas de evidencia sugieren que la función de las células dendríticas es alterada por T. cruzi. Es así como células dendríticas derivadas de monocitos pueden ser infectadas por el parásito, permitiendo su multiplicación intracelular con consecuencias funcionales en células dendríticas inmaduras y alteración de su maduración inducida por el lipopolisacárido (LPS) (7). Estas alteraciones funcionales incluyen disminución de la producción de la interleucina-12 (IL-12), factor de necrosis tumoral $\alpha$ (TNF $\alpha$ ) y de la expresión de moléculas de superficie tales como HLA-DR y CD40. También se ha visto que células dendríticas infectadas con $T$. cruzi tienen poca capacidad para presentar péptidos antigénicos a células T CD8+ y, por lo tanto, inducen bajos niveles de interferón gamma (IFN $\gamma$ ), efecto probablemente relacionado con la disminución en la expresión de moléculas de clase I del sistema mayor de histocompatibilidad (8).

Aunque diferentes antígenos del parásito han sido caracterizados y examinados para estudiar su capacidad de estimulación de respuesta inmune, son pocos los que han demostrado capacidad para inducir respuesta protectora (9-11). Así, la proteína 
11 de membrana de los cinetoplástidos, KMP-11, fusionada a la proteína de choque térmico HSP70 del parásito, induce tanto inmunidad humoral como celular en ratones y también es capaz de proteger a los animales inmunizados frente a un posterior reto con el parásito $(9,12)$. Adicionalmente, el péptido correspondiente a los aminoácidos 4 a 12 de la región N-terminal de la proteína KMP-11 de $T$. cruzi, denominado $\mathrm{K} 1$, es un epítope inmunodominante en la inducción de respuesta citotóxica de células T CD8+ de ratones inmunizados con la proteína de fusión KMP-11/HSP70 (9). Así mismo, estudios recientes en pacientes chagásicos demuestran que el péptido $\mathrm{K} 1$ no sólo es reconocido y procesado de manera natural durante la infección, sino que induce la producción de IFN $\gamma$ por parte de linfocitos T CD8+, los cuales presentan, además, actividad citotóxica (13).

Teniendo en cuenta la importancia de las células dendríticas en la inducción de respuesta inmune y el papel de la proteína KMP-11 en la inducción de inmunidad protectora en los modelos estudiados, en el presente estudio se evaluó el potencial para inducir la maduración in vitro de células dendríticas derivadas de monocitos de pacientes chagásicos crónicos por parte de la proteína KMP-11 y el péptido K1 de T. cruzi.

\section{Materiales y métodos}

\section{Población en estudio}

Se seleccionaron siete pacientes con cardiomiopatía chagásica crónica, con edades comprendidas entre 35 y 85 años, que acudieron a la consulta de Cardiología del Hospital San Ignacio, Bogotá, Colombia. Dichos pacientes presentaron historia clínica, exámenes de diagnóstico clínico (electrocardiograma), prueba tamiz (Chagatek ${ }^{\circledR}$ ) y pruebas confirmatorias (inmunofluorescencia indirecta y ELISA) compatibles con la enfermedad. Con el fin de comparar los resultados obtenidos, se incluyeron siete individuos controles sanos del mismo grupo de edad, que acudieron voluntariamente al Hospital San Ignacio, cuyas pruebas serológicas para $T$. cruzi fueron negativas y el examen clínico, normal. El presente estudio fue evaluado y aprobado por el Comité de Ética de la Facultad de Ciencias de la Pontificia Universidad Javeriana.

\section{Síntesis del péptido K1 y obtención de la proteína KMP-11}

El péptido sintético K1 (TLEEFSAKL) de la proteína KMP-11 ${ }_{4-12}$ (9) fue sintetizado en fase sólida y purificado mediante cromatografía líquida de alta presión (HPLC) (14). La proteína recombinante KMP-11 se obtuvo de acuerdo con lo reportado previamente (15). Brevemente, el ADN correspondiente a la región codificante de la proteína fue digerido con las enzimas Mscl y Rsal, subclonado en el vector de expresión $\mathrm{pQE}_{31}$ y expresado en células de Escherichia coli.

\section{Obtención de células dendríticas derivadas de monocitos e inducción del proceso de maduración}

A partir de $40 \mathrm{ml}$ de sangre anticoagulada con heparina se obtuvieron células mononucleares de sangre periférica (CMSP) por gradientes de densidad con Ficoll-Hypaque (Sigma, St Louis, MO). Los monocitos fueron separados con anticuerpos monoclonales anti-CD14 (BD Pharmingen) acoplados a perlas magnéticas utilizando el sistema de MiniMaCs (Miltenyi Biotech GMBH, Bergisch, Gladbach, Germany). Las células obtenidas fueron lavadas en medio base RPMI 1640 (Invitrogen, Life Tecnologies, Carlsbad, CA) suplementado con $2 \%$ de suero fetal bovino (SFB, Sigma, St Louis, MO). La viabilidad y el número de las células se evaluaron por medio de coloración con azul de tripán y conteo celular en cámara de Newbauer, respectivamente. La pureza de la población se evaluó por citometría de flujo utilizando el anticuerpo anti-CD14.PE (BD Pharmingen). Las células CD14+ así obtenidas fueron diferenciadas a células dendríticas inmaduras mediante incubación en medio RPMI 1640 completo (antibióticos, aminoácidos no esenciales, piruvato de sodio y $10 \%$ de SFB) en placas de 48 pozos a una densidad de $5 \times 10^{5}$ por $\mathrm{ml}$ en presencia de $1.000 \mathrm{U} / \mathrm{ml}$ de IL-4 y $50 \mathrm{ng} / \mathrm{ml}$ de GM-CSF (R\&D system) durante 5 días de cultivo, verificándose su morfología por microscopía de luz. En el día 5 se adicionaron $6 \mu \mathrm{g} / \mathrm{ml}$ de KMP11 en presencia o ausencia de $10 \mu \mathrm{g} / \mathrm{ml}$ de polimixina $B$ durante 48 horas. Por otra parte, 10 $\mu \mathrm{g} / \mathrm{ml}$ del péptido $\mathrm{K} 1$ fueron adicionados en presencia o ausencia de $1 \mu \mathrm{g} / \mathrm{ml}$ de LPS durante 48 horas. Cada ensayo se realizó por duplicado. 
Como control positivo de maduración se utilizó 1 $\mu \mathrm{g} / \mathrm{ml}$ de LPS. Como control negativo, se cultivaron las células dendríticas inmaduras sin estímulo de maduración durante 7 días. La presencia de marcadores de células dendríticas maduras se evaluó por citometría de flujo (16). Todos los reactivos fueron probados para la presencia de LPS mediante la prueba de amebocitos de Lymulus spp. (Bio Whittaker).

\section{Determinación de marcadores celulares por citometría de flujo}

Los marcadores para células dendríticas se evaluaron con anticuerpos anti CD14-APC, CD83FITC, CD86-PE y HLA-DR-PerCP (BD Biosciences). La obtención de los datos se realizó usando un citómetro de flujo FACSCalibur (BD Immunocytometry Systems). Los análisis se realizaron con el programa Cell Quest.

\section{Determinación de la producción de citocinas}

La cuantificación de citocinas en los sobrenadantes de cultivo de las células dendríticas se realizó el día 7 con un estuche comercial de Cytometric Bead Array (CBA, BD Biosciences), en el cual se utilizan perlas de diferentes intensidades de fluorescencia en FL3, cubiertas con anticuerpos de captura fluorescentes en FL2 para IL-8, IL-1 $\beta$, IL-6, IL-10, TNF $\alpha$ e IL-12p70. El cálculo de la concentración se realizó utilizando patrones de las diferentes citocinas en concentraciones conocidas. La obtención de los datos se realizó usando un citómetro de flujo FACSCalibur (BD Immunocytometry Systems). Para la adquisición y análisis de los datos, se utilizó el programa Cell Quest.

\section{Análisis de los resultados}

Los resultados se muestran como el promedio y el error estándar de la media. Para establecer diferencias significativas, se utilizó la prueba no paramétrica U de Mann-Withney con un nivel de significación de 0,05.

\section{Resultados}

El aislamiento de monocitos de sangre periférica por selección positiva permitió obtener poblaciones de células CD14+ con purezas mayores al 92\%. Con el fin de evaluar el efecto de la proteína KMP11 y el péptido $\mathrm{K} 1$ sobre la expresión de marcadores de células dendríticas de pacientes con Chagas y controles sanos, se utilizaron células dendríticas diferenciadas a partir de monocitos de sangre periférica (células dendríticas inmaduras), las cuales fueron expuestas a la proteína KMP-11 en presencia o ausencia de polimixina $B O$ al péptido $K 1$ en presencia o ausencia de LPS. Aunque la prueba para detección de LPS en todos los reactivos utilizados fue negativa, se utilizó polimixina $B$ en los cultivos expuestos a la proteína KMP-11 como inhibidor de la actividad de la endotoxina que pudiera estar presente en niveles no detectables por la prueba de amebocitos de Lymulus spp., con sensibilidad de $0,1 \mathrm{UE} / \mathrm{ml}$.

En todos los casos, la adición de IL-4 y GM-CSF a los monocitos de sangre periférica indujo la pérdida en la expresión de la molécula CD14, lo cual indica que los monocitos se diferenciaron a células dendríticas (datos no mostrados). Estas células expresaron CD86 y HLA-DR y la exposición al estímulo de maduración (LPS) indujo un aumento en su expresión, así como la expresión del marcador de maduración CD83, sin diferencia entre pacientes y controles sanos (figura 1).

\section{Expresión de marcadores de células dendríticas expuestas a la proteína KMP-11}

La exposición de células dendríticas inmaduras de pacientes a la proteína KMP-11 de $T$. cruzi indujo una disminución no significativa del marcador de coestimulación CD86 en comparación con los controles sanos (figura 2A). En cuanto a la expresión de HLA-DR, no se observaron diferencias de expresión tras la adición de la proteína KMP-11 en las células dendríticas inmaduras procedentes de pacientes chagásicos ni en las procedentes de controles sanos (figura 2A). La adición de polimixina B no originó modificación alguna del patrón de expresión observado. La adición de la proteína KMP-11 a células dendríticas inmaduras no indujo la expresión del marcador de maduración CD83.

\section{Expresión de marcadores de células dendríticas expuestas al péptido $\mathrm{K} 1$}

Al igual que lo observado para la proteína KMP11 , la adición del péptido K1 a células dendríticas 


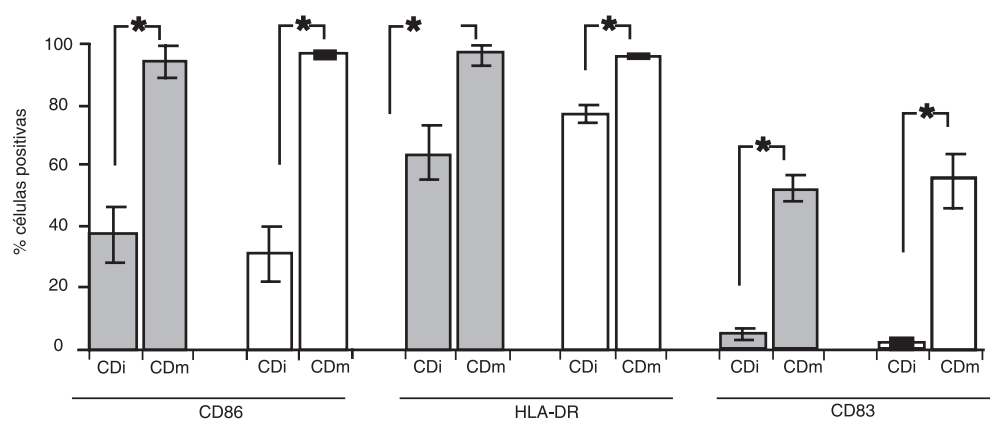

Figura 1. Expresión de marcadores en células dendríticas de 7 pacientes chagásicos (gris) y 7 controles sanos (blanco) expuestas a LPS. Células dendríticas inmaduras (CDi) fueron diferenciadas a partir de monocitos CD14+ en presencia de IL-4 y GM-CSF durante cinco días de cultivo. Para la obtención de células dendríticas maduras (CDm), las CDi previamente obtenidas fueron expuestas durante $48 \mathrm{~h}$ a LPS. Los datos se muestran como promedio del porcentaje de células que expresan los distintos marcadores analizados. Las barras sobre las columnas indican el error estándar de la media (ESM). La significancia estadística de la diferencia de la expresión de los marcadores entre CDi y CDm fue de $p=0,007$ para CD86 y CD83 en células de pacientes y controles, $p=0,02$ para HLA-DR en las células de los pacientes y $p=0,007$ en las de los controles.

A.

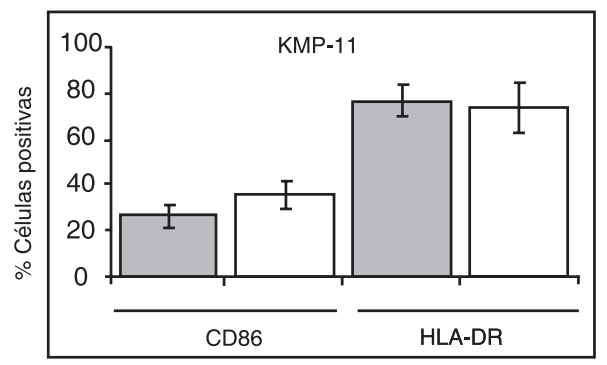

B.

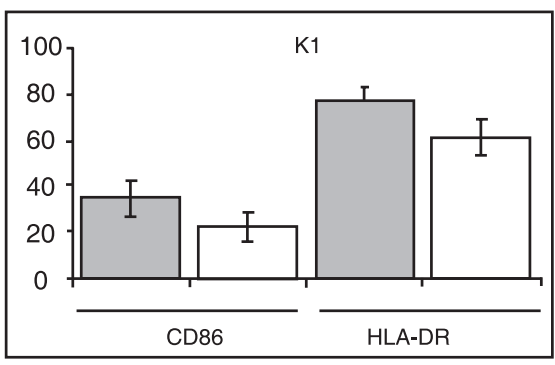

Figura 2. Expresión de marcadores en células dendríticas inmaduras de 7 pacientes chagásicos (gris) y 7 controles sanos (blanco) estimuladas con la proteína KMP-11 (A) y el péptido K1 (B) el día 5 de cultivo durante 48 h. Los datos se muestran como promedio del porcentaje de células que expresan los distintos marcadores analizados. Las barras sobre las columnas indican el error estándar de la media (ESM).

de pacientes chagásicos y controles sanos no indujo la expresión del marcador de maduración CD83. La adición del péptido $\mathrm{K} 1$ a células dendríticas inmaduras indujo en las células de los pacientes chagásicos un incremento estadísticamente no significativo en la expresión de CD86 y HLA-DR comparado con los niveles observados en controles sanos (figura 2B).

Con el propósito de evaluar el efecto del péptido $\mathrm{K} 1$ en la maduración de células dendríticas inducida por la adición de LPS, se expusieron células dendríticas inmaduras simultáneamente al péptido K1 y a LPS en el día 5 de cultivo. Los resultados obtenidos mostraron que la adición del péptido $\mathrm{K} 1$ dio lugar a una disminución estadísticamente significativa en la expresión de las moléculas CD86 $(p=0,004)$ y CD83 $(p=0,003)$ frente a la que mostraron las células dendríticas incubadas únicamente con LPS (figuras $3 \mathrm{~A}$ y $3 \mathrm{~B}$ ). Sin embargo, los resultados obtenidos no mostraron diferencias en la expresión de HLA-DR en las células de pacientes o individuos sanos incubadas con K1 y LPS con respecto a lo observado en células dendríticas expuestas únicamente a LPS (figura 3C).

\section{Determinación de las citocinas secretadas por las células dendríticas}

Con el fin de evaluar la actividad funcional de las células dendríticas frente a los diferentes estímulos, se procedió a cuantificar la producción de varias citocinas (IL-1 $\beta$, TNF- $\alpha$, IL-6, IL-8, IL10 e IL-12) en el sobrenadante de los cultivos. Al 
comparar las células dendríticas de pacientes y controles en presencia de LPS con o sin el péptido $\mathrm{K} 1$, no se observaron diferencias significativas en la producción de citocinas. Sin embargo, los resultados mostraron un descenso estadísticamente significativo $(p=0,02)$ en la secreción de IL-12 por parte de las células dendríticas de pacientes chagásicos expuestas al péptido $\mathrm{K} 1 \mathrm{y}$ LPS comparado con las células dendríticas de controles sanos igualmente tratadas (figura 4A). Además, se observó un aumento estadísticamente no significativo en la secreción de IL-10 por parte de las mencionadas células dendríticas de los pacientes chagásicos en comparación a los niveles observados en las células de controles sanos (figura 4B). No se observaron diferencias en los niveles de las citocinas IL- $1 \beta$, TNF- $\alpha$, IL- 6 e IL-8 de las células dendríticas de pacientes chagásicos versus las de controles sanos tratadas ambas con K1 y LPS (datos no mostrados).

\section{Discusión}

Las células dendríticas regulan la respuesta inmune local y sistémica mediante la expresión de moléculas en su superficie y de moléculas secretadas que generan señales que influencian el crecimiento, la muerte y la diferenciación de la célula $T(17,18)$. Las células dendríticas tienen la capacidad de inducir la polarización de la respuesta linfoide hacia Th1 o Th2, dependiendo del patrón de moléculas que expresen o secreten. Por ejemplo, la secreción de IL-12 por células dendríticas induce la generación de células $T$ de tipo Th1 $(19,20)$.

Además de su papel inductor de la respuesta linfoide, recientemente han surgido algunas líneas de evidencia que sugieren que las células dendríticas pueden tener un papel regulador en la inducción de tolerancia periférica. Es así como se ha mostrado que células dendríticas en estado inmaduro o semimaduro pueden inducir la activación de células T reguladoras (21).

En el caso de la respuesta inmune a agentes infecciosos es de particular interés el hecho de que algunos patógenos pueden inducir la generación de células dendríticas reguladoras que inhiben la inducción de respuesta inmune efectiva, lo cual se relaciona con estrategias de evasión
A.

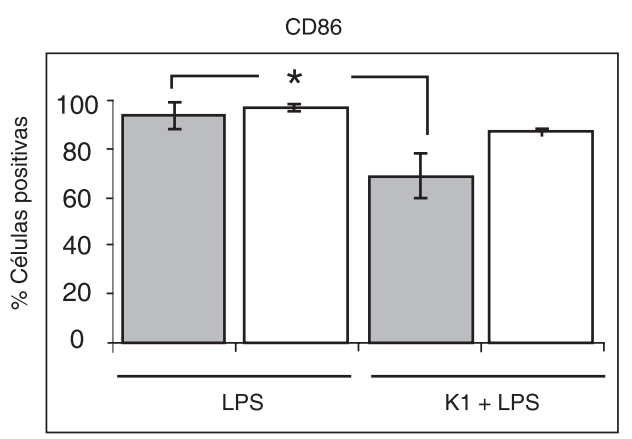

B.

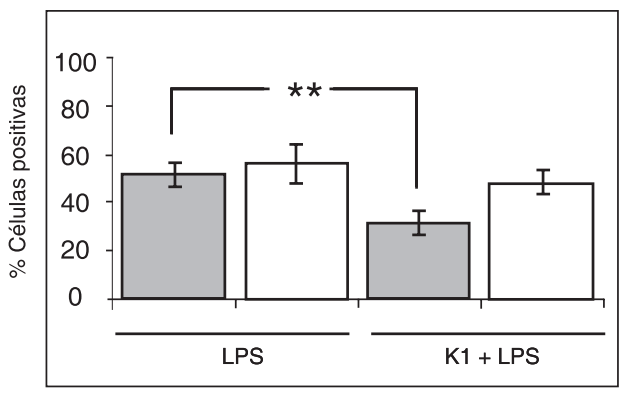

c.

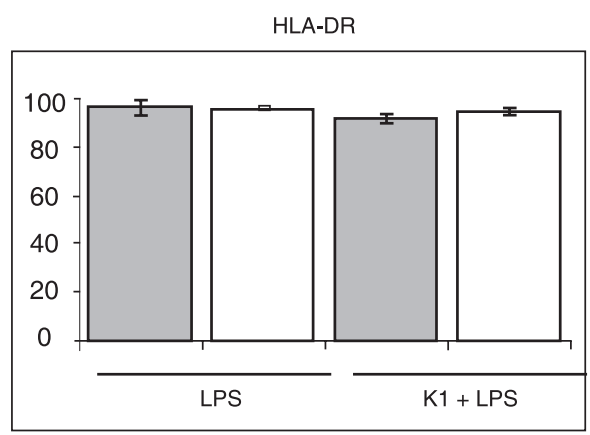

Figura 3. Expresión de marcadores en células dendríticas maduras de 7 pacientes (gris) y 7 controles sanos (blanco) estimuladas con LPS o el péptido K1 y LPS (K1+LPS) el día 5 de cultivo durante $48 \mathrm{~h}$. Los datos se muestran como promedio del porcentaje de células que expresan los distintos marcadores analizados. Las barras sobre las columnas indican el error estándar de la media (ESM). La significación estadística de la diferencia de la expresión de los marcadores entre células dendríticas de pacientes estimuladas con LPS o K1+LPS fue de $p=0,004$ para CD86 y $p=0,03$ para CD83. 
A.

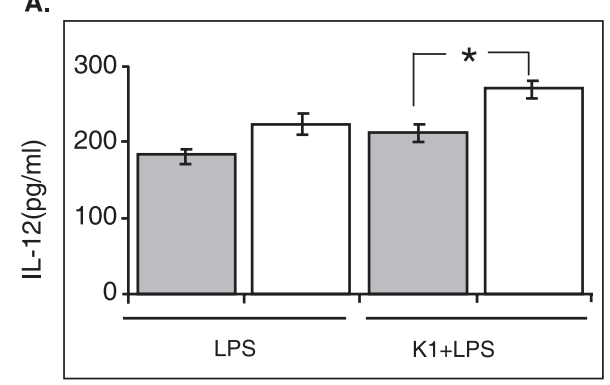

B.

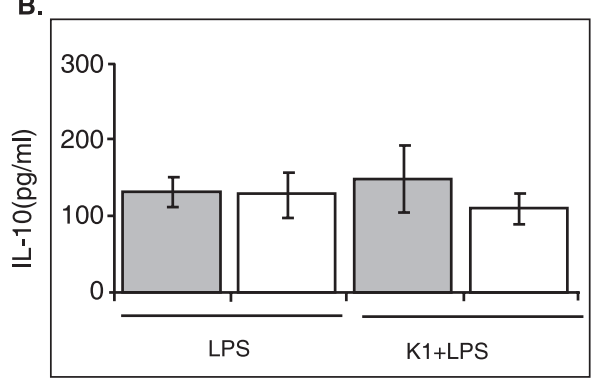

Figura 4. Cuantificación de citocinas por citometría de flujo de células dendríticas de 7 pacientes (gris) y 7 controles sanos (blanco) expuestas a LPS o al péptido K1 y LPS (K1+LPS) el día 5 de cultivo durante $48 \mathrm{~h}$. Los datos se muestran como promedio del porcentaje de células que expresan los distintos marcadores analizados. Las barras sobre las columnas indican el error estándar de la media (ESM). La significación estadística de la diferencia de la producción de IL-12 e IL 10 entre las células dendríticas de pacientes y controles estimuladas con K1 y LPS fue de $p=0,02$ y $p>0,05$, repectivamente.

de la respuesta inmune por estos agentes y explica en parte la cronicidad de algunas enfermedades infecciosas $(22,23)$.

Los estudios sobre la interacción de las células dendríticas y $T$. cruzi muestran que el parásito puede infectar dichas células y multiplicarse en su interior alterando el programa de maduración de la célula dendrítica mediante la inhibición de la producción de citocinas, disminución de moléculas coestimuladoras (7), disminución de la expresión de moléculas de clase I y, por lo tanto, alteración de la capacidad para presentar péptidos antigénicos a linfocitos T CD8+ (8). Algunas moléculas, como los glicoinositolfosfolípidos (GIPL), han sido relacionadas con esta hiporreactividad inmune del parásito (24). Sin embargo, otras moléculas como la proteína Tc52, que es una oxidorreductasa necesaria para la supervivencia y la virulencia del parásito, induce maduración de células dendríticas derivadas de monocitos y protege ratones in vivo frente a una infección letal con T. cruzi (25), lo cual indica que aunque la infección de la célula dendrítica por $T$. cruzi altera su actividad en términos de estimulación de células $T$, algunas moléculas derivadas de éste podrían considerarse como buenos candidatos para la generación de vacunas específicas contra el parásito.

La proteína 11 de membrana de cinetoplástidos (KMP-11) fue descrita en Leishmania donovani asociada al lipofosfoglicano (LPG) (26), localizada en el bolsillo flagelar y asociada al citoesqueleto; esta proteína se considera una estructura crítica para la movilidad del parásito y para su unión a la célula hospedera $(27,28)$. La presencia de la KMP11 ha sido demostrada en varias especies de leishmanias y tripanosomas, y no ha sido descrita en otros organismos diferentes a los cinetoplástidos, lo cual respalda el concepto de un rol específico en estos parásitos (28).

Con base en los estudios que demuestran la importancia de la proteína KMP-11 y de su péptido $\mathrm{K} 1$ en la respuesta inmune frente a la infección $(9,12,13,15)$, en este trabajo se evaluó la expresión de marcadores de maduración en células dendríticas derivadas de monocitos de pacientes chagásicos crónicos e individuos sanos estimuladas con la proteína KMP-11 y el péptido $\mathrm{K} 1$ de $T$. cruzi. Vale la pena anotar que estudios preliminares realizados por nuestro grupo indican que el péptido $\mathrm{K} 1$ induce una respuesta inmune humoral específica en pacientes infectados independientemente de su tipo de HLA (29), a pesar de haber sido reportado como un epítope restringido al $\mathrm{HLA}-\mathrm{A}^{*} 0201$ en trabajos previos $(9,13)$.

Los resultados obtenidos en este estudio muestran que si bien la proteína KMP-11 no induce la maduración de células dendríticas, su péptido amino terminal K1 en presencia de LPS se asocia con una menor expresión de los marcadores CD83 y CD86 en las células dendríticas de los pacientes. Por otra parte, la respuesta in vitro frente al péptido $\mathrm{K} 1$ en presencia de LPS muestra niveles 
significativamente inferiores en la producción de IL-12 por las células dendríticas de los pacientes. Estos resultados sugieren que K1 en presencia de LPS tiene un efecto en el programa de maduración de las células dendríticas que es característico de pacientes chagásicos, el cual podría afectar la estimulación de los linfocitos $\mathrm{T}$, así como también interferir con la polarización hacia una respuesta Th1, la cual se ha visto que es crucial para el control de la infección por $T$. cruzi, al menos en los modelos murinos (30-32).

Una posible explicación a esta disminución en la expresión de marcadores de membrana podría deberse a un efecto tóxico de la proteína o del péptido sobre las células. Sin embargo, el hecho de encontrar disminución en la expresión de las moléculas mencionadas en las células de los pacientes chagásicos y no en las de los controles sanos parece indicar que éste no es el caso. Además, el efecto de K1 y LPS se observa para la expresión de CD86 y CD83, mientras que la expresión de HLA-DR no se ve afectada.

Si bien el papel de antígenos específicos parasitarios en la maduración de células dendríticas murinas ha sido descrito previamente, como es el caso de la proteína HSP70 de T. cruzi (33), este es el primer reporte que involucra a un péptido sintético derivado de una proteína del parásito en esta modulación. El mecanismo molecular mediante el cual K1 ejerce su acción es desconocido; sin embargo, llama la atención que otros péptidos derivados de patógenos tales como el péptido sintético T20 del virus de inmunodeficiencia adquirida 1 (HIV-1) y el péptido $\mathrm{Hp}(2-20)$ de Helicobacter pylori inhiben la producción de IL-12 por parte de monocitos humanos $(34,35)$. Se ha visto que estos péptidos son agonistas de la familia de receptores FPR (formyl peptide receptor) (36-38). Así mismo, el péptido sintético WKYMVm, agonista de FPR y FPRL2, inhibe tanto la maduración de células dendríticas humanas como la producción de IL12 de las mismas (35). Adicionalmente, también se ha encontrado que el LPS es capaz de aumentar la expresión de FPR y FPRL1 en macrófagos y neutrófilos de ratones (39). Por lo tanto, es de especial interés investigar si K1 en presencia de LPS, es capaz de interactuar con estos receptores, desencadenando una disminución en la producción de IL-12.

El hecho de que el efecto de $\mathrm{K} 1$ en presencia de LPS sólo se observe en pacientes infectados y no en individuos sanos llama la atención por cuanto las células dendríticas hacen parte de la respuesta inmune innata y sugiere que de alguna manera el contacto previo con el parásito o algunas de sus moléculas alteraría el programa de maduración de tales células.

Por otra parte, es posible que la diferencia en el comportamiento del péptido $\mathrm{K} 1$ en presencia de LPS y de la proteína KMP-11 se deba esencialmente a la diferencia estructural y antigénica entre las dos moléculas, lo que conllevaría a la activación de distintas vías de la respuesta inmune.

Queda por determinar si el sistema de estimulación descrito en este trabajo es reproducible en pacientes infectados asintomáticos para poder llegar a conclusiones sobre el papel del péptido $\mathrm{K} 1$ en la modulación de la respuesta inmune específica in vivo.

\section{Conflicto de intereses}

Los autores manifestamos expresamente que durante la realización del presente trabajo no existió conflicto de interés alguno que pudiera afectar los resultados obtenidos.

\section{Agradecimientos}

Los autores expresan su agradecimiento a Miguel Vacca del Hospital Universitario San Ignacio, PUJB, a Rubén Santiago Nicholls, a Marleny Montilla y Astrid C. Flórez del Laboratorio de Parasitología del Instituto Nacional de Salud y a Marcela Mercado del Grupo de Enfermedades Infecciosas, PUJB, por su colaboración en la evaluación clínica de los pacientes y la realización de las pruebas de laboratorio IFI, ELISA y Chagatek $\circledast$, respectivamente.

\section{Financiación}

Este estudio fue financiado por la Vicerrectoria Académica de la Pontificia Universidad Javeriana. Registro de proyecto 1767. 


\section{Referencias}

1. Revy $\mathbf{P}$, Sosperda $\mathbf{M}$, Barbour B, Trautmann A. Functional antigen-independent synapses formed between $T$ cells and dendritic cells. Nat Immunol 2001;2:925-31.

2. Russo V, Tanzarella S, Dalerba P, Rigatti D, Rovere $\mathbf{P}$, Villa $\mathbf{A}$, et al. Dendritic cells acquire the MAGE-3 human tumor antigen from apoptotic cells and induce a class I restricted T cell response. Proc Natl Acad Sci USA 2000;97:2185-90.

3. Lanzavecchia A, Sallusto $\mathbf{F}$. The instructive role of dendritic cells on $\mathrm{T}$ cell responses: lineages, plasticity and kinetics. Curr Opin Immunol 2001;13:291-8.

4. World Health Organization. Control of Chagas disease. Second report of the WHO Expert Committee, Technical Report 2002, Series 905. Geneva: WHO; 2002. p.39-40.

5. Moncayo A. Chagas disease: current epidemiological trends after the interruption of vectorial and transfusional transmission in the Southern Cone countries. Mem Inst Oswaldo Cruz 2003;98:577-91.

6. Tanowitz HB, Kirchhoff LV, Simon D, Morris SA, Weiss LM, Wittner M. Chagas' disease. Clin Microbiol Rev 1992;5:400-19.

7. Van Overtvelt L, Vanderheyde $N$, Verhasselt V, Ismaili J, De Vos L, Goldman M, et al. Trypanosoma cruzi infects human dendritic cells and prevents their maturation: inhibition of cytokines, HLA-DR, and costimulatory molecules. Infect Immun 1999;67:4033-40.

8. Van Overtvelt L, Andrieu M, Verhasselt V, Connan F, Choppin J, Vercruysse V, et al. Trypanosoma cruzi down-regulates lipopolysaccharide-induced MHC class I on human dendritic cells and impairs antigen presentation to specific CD8(+) T Iymphocytes. Int Immunol 2002;14:1135-44.

9. Marañon C, Thomas MC, Planelles L, Lopez MC. The immunization of $A 2 / K(b)$ transgenic mice with the KMP-11-HSP70 fusion protein induces CTL response against human cells expressing the $T$. cruzi KMP-11 antigen: Identification of A2-restricted epitopes. Mol Immunol 2001;38:279-87.

10. Rodrigues MM, Ribeirao M, Pereira-Chioccola V, Renia L, Costa F. Predominance of CD4 Th1 and CD8 Tc1 cells revealed by characterization of the cellular immune response generated by immunization with a DNA vaccine containing a Trypanosoma cruzi gene. Infect Immun 1999;67:3855-63.

11. Villalta F, Lima MF, Howard SA, Zhou L, Ruíz-Ruano A. Purification of a Trypanosoma cruzi trypomastigote 60 -Kilodalton surface glycoprotein that primes and activates murine lymphocytes. Infect Immun 1992;60:3025-32.

12. Planelles L, Thomas MC, Alonso C, Lopez MC. DNA immunization with Trypanosoma cruzi HSP70 fused to the KMP-11 protein elicits a cytotoxic and humoral immune response against the antigen and leads to protection. Infect Immun 2001;69:6558-63.

13. Diez H, López MC, Thomas MC, Guzman F, Rosas $\mathrm{F}$, Velazco V. et al. Evaluation of IFNg production by CD8+ $\mathrm{T}$ lymphocytes in response to the $\mathrm{K} 1$ peptide from KMP-11 protein in patients infected with Trypanosoma cruzi. Parasite Immunol 2006;28:101-5.

14. Chaves F, Calvo JC, Carvajal C, Rivera Z, Ramirez $\mathrm{L}$, Pinto $\mathbf{M}$, et al. Synthesis, isolation and characterization of Plasmodium falciparum antigenic tetrabranched peptide dendrimers obtained by thiazolidine linkages. J Pept Res 2001;58:307-16.

15. Thomas MC, Longobardo MV, Carmelo E, Maranon C, Planelles L, Patarroyo ME, et al. Mapping of the antigenic determinants of the $T$. cruzi kinetoplastid membrane protein-11. Identification of a linear epitope specifically recognized by human Chagasic sera. Clin Exp Immunol 2001;123:465-71.

16. Cuéllar A, Fonseca A, Gómez A. Efecto del lipopolisacárido en cultivos de células dendríticas humanas y su inhibición por la polimixina B. Biomédica 2004;24:413-22.

17. Modlin RL, Brightbill HD, Godowski PJ. The toll of innate immunity on microbial pathogens. N Engl J Med 1999;340:1834-5.

18. Lanzavecchia A, Sallusto $\mathbf{F}$. Dynamics of $T$ lymphocyte responses: intermediates, effectors, and memory cells. Science 2000;290:92-7.

19. Moser M, Murphy KM. Dendritic cell regulation of TH1TH2 development. Nat Immunol 2000;1:199-205.

20. Pearce EJ, Kane CM, Sun J. Regulation of dendritic cell function by pathogen-derived molecules plays a key role in dictating the outcome of the adaptive immune response. Chem Immunol Allergy 2006;90:82-90.

21. Lutz MB, Schuler G. Immature, semi-mature and fully mature dendritic cells: which signals induce tolerance or immunity? Trends Immunol 2002;23:445-9.

22. Smits HH, Engering A, van der Kleij D, De Jong EC, Schipper K, van Capel TM, et al. Selective probiotic bacteria induce IL-10-producing regulatory $\mathrm{T}$ cells in vitro by modulating dendritic cell function through dendritic cell-specific intercellular adhesion molecule 3-grabbing nonintegrin. J Allergy Clin Immunol 2005;115:1260-7.

23. Auffermann-Gretzinger S, Keeffe EB, Levy S. Impaired dendritic cell maturation in patients with chronic, but not resolved, hepatitis $C$ virus infection. Blood 2001;97:3171-6.

24. Brodskyn C, Patricio J, Oliveira R, Lobo L, Arnholdt A, Mendonca-Previato $L$, et al. Glycoinositolphospholipids from Trypanosoma cruzi interfere with macrophages and dendritic cell responses. Infect Immun 2002;70:3736-43. 
25. Ouaissi A, Guilvard E, Delneste Y, Caron G, Magistrelli G, Herbault N, et al. The Trypanosoma cruzi Tc52-released protein induces human dendritic cell maturation, signals via toll-like receptor 2 , and confers protection against lethal infection. J Immunol 2002;168:6366-74.

26. Jardim A, Hanson S, Ullman B, McCubbin WD, Kay CM, Olafson RW. Cloning and structure-function analysis of the Leishmania donovanni kinetoplastid membrane protein-11. Biochem J 1995;305:315-20.

27. Thomas MC, García-Pérez JL, Alonso C, López MC. Molecular characterization of KMP-11 from Trypanosoma cruzi: a cytoskeleton-associated protein regulated at the translational level. DNA Cell Biol 2000;19:47-57.

28. Stebeck CE, Baron GS, Beecroft RP, Pearson TW. Molecular characterization of the kinetoplastid membrane protein-11 from African trypanosomes. Mol Biochem Parasitol 1996;81:81-8.

29. Diez H, López MC, Thomas MC, Guzman F, Rosas F, Velasco V, et al. Respuesta inmune al péptido K1 en pacientes infectados con Trypanosoma cruzi. Parasitol Latin 2005;60:208.

30. Hoft DF, Eickhoff CS. Type 1 immunity provides optimal protection against both mucosal and systemic Trypanosoma cruzi challenges. Infect Immun 2002;70:6715-25.

31. Kumar S, Tarleton RL. Antigen-specific Th1 but not Th2 cells provide protection from lethal Trypanosoma cruzi infection in mice. J Immunol 2001;166:4596-603.

32. Planelles L, Thomas MC, Marañon C, Morell M, López MC. Differential CD86 and CD40 co-stimulatory molecules and cytokine expression pattern induced by Trypanosoma cruzi in APCs from resistant or susceptible mice. Clin Exp Immunol 2003;131:41-7.
33. Planelles L, Thomas M, Pulgar M, Marañon C, Grabbe S, López MC. Trypanosoma cruzi heat-shock protein-70 kDa, alone or fused to the parasite KMP-11 antigen, induces functional maturation of murine dendritic cells. Immunol Cell Biol 2002;80:241-7.

34. Braun MC, Wang JM, Lahey E, Rabin RL, Kelsall BL. Activation of the formyl peptide receptor by the HIV-derived peptide T-20 suppresses interleukin-12 p70 production by human monocytes. Blood 2001;97: 3531-6.

35. Kang HK, Lee HY, Kim MK, Park KS, Park YM, Kwak JY, et al. The synthetic peptide Trp-Lys-Tyr-Met-ValD-Met inhibits human monocyte-derived dendritic cell maturation via formyl peptide receptor and formyl peptide receptor-like 2. J Immunol 2005;175:685-92.

36. Betten A, Bylund J, Cristophe T, Boulay F, Romero A, Hellstrand $\mathrm{K}$, et al. A proinflammatory peptide from Helicobacter pylori activates monocytes to induce lymphocyte dysfunction and apoptosis. J Clin Invest 2001;108:1221-8.

37. Hartt JK, Liang T, Sahagun-Ruiz A, Wang JM, Gao JL, Murphy PM. The HIV-1 cell entry inhibitor T-20 potently chemoattracts neutrophils by specifically activating the $\mathrm{N}$-formylpeptide receptor. Biochem Biophys Res Commun 2000;272:699-704.

38. Bylund J, Christophe T, Boulay F, Nystrom T, Karlsson A, Dahlgren C. Proinflammatory activity of a cecropin-like antibacterial peptide from Helicobacter pylori. Antimicrob Agents Chemother 2001;45:1700-4.

39. Mandal $P$, Novotny $M$, Hamilton TA. Lipopolysaccharide induces formyl peptide receptor 1 gene expression in macrophages and neutrophils via transcriptional and posttranscriptional mechanisms. J Immunol 2005;175:6085-91. 